\title{
Life Cycle Costing Method
}

\author{
Real Jagdishsingh, Rahul S Patil \\ P.G student from Department of Civil Engineering, Padamshree Dr. D. Y Patil institute of Engineering \& \\ Technology. Pimpri Pune. \\ Assistant Professor in Department of Civil Engineering, Padamshree Dr. D. Y Patil institute of Engineering \& \\ Technology. Pimpri Pune.
}

\begin{abstract}
The determination of the costs is an integral part of the asset management process and is basic factor in the facility management toolbox, particularly for economic, financial appraisal, Value engineering and Risk analysis. In the past comparisons of project alternatives whether at the concept level or a detailed design level have been made purely on the initial capital cost parameters. But with the promoter now becoming the life time owner of the facility, he is now supposed to maintain and operate the facility and now that is not someone else but his own responsibility.

Life Cycle Cost can be called as an economic analysis procedure that uses engineering inputs to compare competing alternatives all significant costs and express the results in equivalent rupees.

Life cycle costing is a concept wherein project alternatives are selected based on the total costs that incur over the life of the project right from inception to the creation to operations and maintenance to final disposal after the expiry of the useful life span of the project.

Index Terms:LCC, Life span, Capital Cost, operation and maintenance cost.
\end{abstract}

\section{Introduction}

With the current trend there is growing need to create a facility wherein the facility has the least of cost of ownership (Which includes the capital expenses plus maintenance and operation cost as well). Similarly growing pressure to achieve better outcomes from assets means that ongoing operating and maintenance costs must be taken into consideration as they are more often more than the initial capital cost. The Cost incurred over the life time of the facility in the present consideration of a building project the total Cost (Initial Capital Cost + Cost of Operation + cost of Maintenance + Cost of demolition or Salvage cost) is called as life cycle costing (LCC). It more realistically means the total cost of a product that can be influenced beforehand and that the various cost factors are interrelated. LCC takes into account all costs of acquiring, owning and disposing of building or building system. The construction industry has focussed on two main factors in the execution of building projects. First factor is the design of the building from the architects points view as regards to aesthetics, the client wants the architect to build a building which is able to satisfy the aesthetic and functional requirements. The second factor is from the contractors point of view is the constructability of the design. These two are the main concerns of the client when the idea of construction of building is under consideration, Therefore the primary focus of the Architect and contractor is on these factors only. Although these are significant factors, however they are not the only factors that should be considered when planning for the facility. LCC will help determine whether the incorporation of a high performance HVAC or Glazing System which requires increased initial cost but can dramatically reduce the operating and maintenance costs, is cost effective or not. Another factor that is receiving significant attention is the cost of the building operations over the life of a building. The combination of economic concepts and IT allows for a more elaborate calculations for the design and construction of a facility than in past. Instead of only looking at the facility in terms of cost to design and build, owners can increase their perspective to include operations, Maintenance, repair, replacement and disposal costs. The sum of Initial and future expenses associated with the construction and operations of a building over a period of time is called as LIFE CYCLE COST of a facility.

\subsection{Initial and Future costs}

\section{Life cycle cost components}

The first component in a LCC analysis is cost. There are two major cost categories by which projects are evaluated in LIFE CYCLE COSTING. They are the first construction cost and second the future maintenance and operation costs. Table 1.0 outlines the individual costs that are to be evaluated within the major cost categories. Defining the exact cost of each cost categories can be little difficult since at the time of LCC study, nearly all costs are unknown, however with the use of reasonable consistent and well documented assumptions , a credible LIFE cycle costing can be prepared. 


\subsection{Residual Value}

One future expense that needs clear understanding is of the salvage value. Salvage value is the net worth of a building at the end of the LIFE CYCLE COSTING study Period. Unlike other future expenses, an alternative salvage value can be positive or negative. Since a LCC is a sum of costs, a negative value means that there is a value associated with the building at the end of the study period. A positive value indicates that there are disposal costs associated with the building at the end of the study period. Zero value indicates that there is no value or cost associated with the building at the end of the study period.

\subsection{Study Period}

The second component of the LCC equation is time. The study period is the period of time over which the ownership and operations expenses are to be evaluated, normally the study period can range from twenty to forty years, depending on the on owners preference, the stability of the users program and the intended life of the facility. The study period is usually less than the life of the facility.

\subsection{Real Discount Rate}

The third component in the LCC equation is the discount rate. The Discount Rate is the rate of interest reflecting the investor's time value of Money. Basically it is the interest rate that would make an investor indifferent as to whether he received a payment now or a greater payment at some time in future. The discount rates can be further defined as Real Discount rate and nominal discount Rate. Real Discount excludes the rate of inflation and the nominal discount rate includes the rate of inflation.

\section{Methodology}

Prior to beginninga life cycle costing, project alternatives need to be selected, these options should be distinctly different and viable solutions to the facility issue under consideration. The chosen option should be the most reasonable and profitable solution to the project problem. A minimum of three different project options should be incorporated into the life cycle costing. A brief description of each project option and why it was chosen should be included in the life cycle costing

There are many ways to perform a life cycle costing. The life cycle costing need only address cost categories that are pertinent to the scope of the project. However to ensure accurate comparison of alternatives, all life cycle costing assessments of the project options must incorporate the same categories.

The First step in the completion of the LCC is to define all the initial costs like construction cost of land purchase etc.

The Second step is to define all the future operations costs of the various options. The Operation costs are annual costs excluding maintenance and repair costs, involved in the operations of the facility. All operation costs are to be discounted to their present value prior to their addition to the Life cycle cost analysis.

The Third cost in the completion of the LIFE CYCLE costing of the project options is to define all the future maintenance and repair costs of the options. It should be noted that there is distinct difference between maintenance and repair costs...

The fourth step in the completion of life cycle of a project alternatives is to define the cost of replacement of the options. Replacement costs are anticipated expenditures to major building components that are required to maintain the usability of the facility.

The final component in the life cycle costing of the project option is to define the salvage value of the various options

Once all the cost components have been generated and discounted to their present values, The cost can be added up to generate the total life cycle cost of the project options. After this has been completed for all the project options, a summary of the project options should be prepared. The summary of the project option includes and compares the total life cycle costs of initial investments, operations and maintenance and repair, replacement and salvage value of all the project options.

\section{Present Worth Analysis}

\section{Equation}

Discounts all future costs and benefits to the present:

$\mathrm{t}=\mathrm{n}$

$\mathrm{PW}=\mathrm{FC}+\square \mathrm{pwf}[\mathrm{MC}+\mathrm{IC}+\mathrm{FRC}+\mathrm{UC}]+\operatorname{pwf}[\mathrm{S}]$

$\mathrm{t}=0$

FC $=$ First (Initial) cost

Construction Management

Land Acquisition 
Site Investigation

Design Services

Construction

Equipment

Technology

Indirect/Administration

$\mathrm{t}=$ Time Period of analysis

Building design for 50 years

MC = Maintenance Cost

Foundation/Substructure

Superstructure

Exterior Wall Systems

False ceiling

Interior Furniture

Interior Specialties

Conveyance Systems

Plumbing Piping

Plumbing Fixtures

Fire Protection Systems

HVAC system

Electrical Service/Equipment

Equipment \& Furnishings

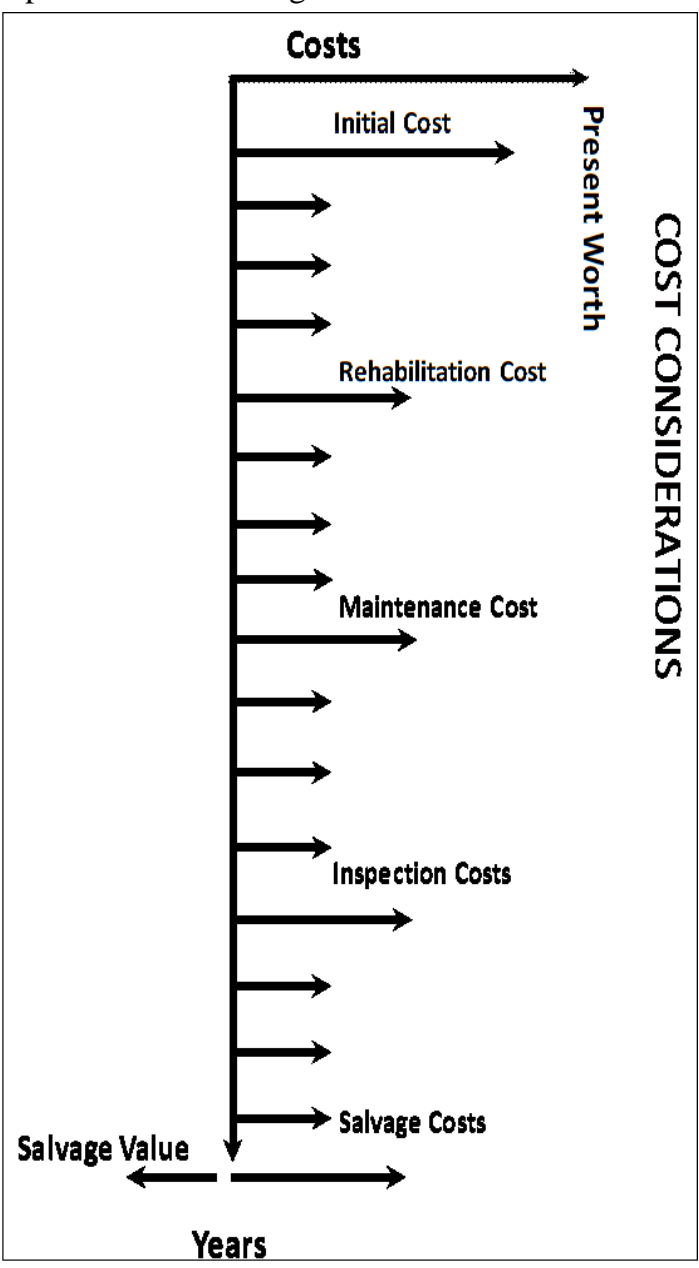

IC = Inspection Costs

Maintenance staff

FRC = Future Rehabilitation Cost

Structure Rehabilitation

Interior

UC = User Costs

Operating cost of HVAC

System

Electrical system

Plumbing and drainage

system

S = Salvage Value for Costs

Demolition cost after end of

life

Pwf = Present worth factor 


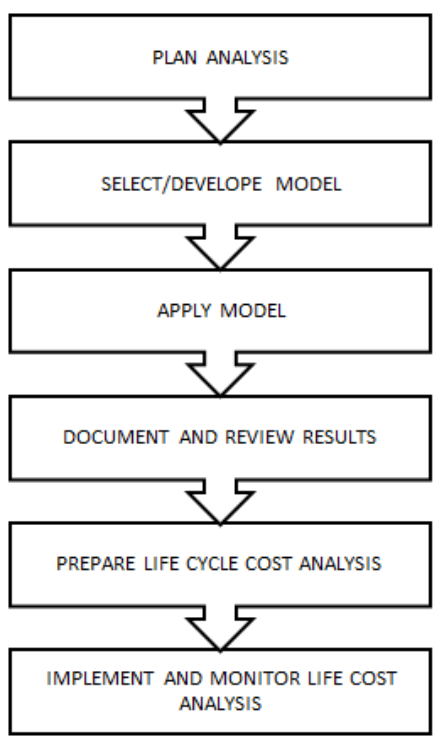

LCC Flow chart

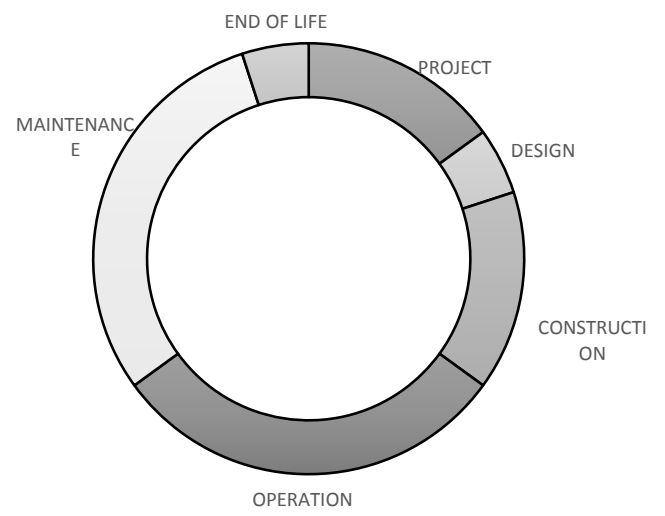

$\square$ PROJECT $\square$ DESIGN

$\square$ CONSTRUCTION $\square$ OPERATION

$\square$ MAINTENANCE $\square$ END OF LIFE

LIFE CYCLE COSTING

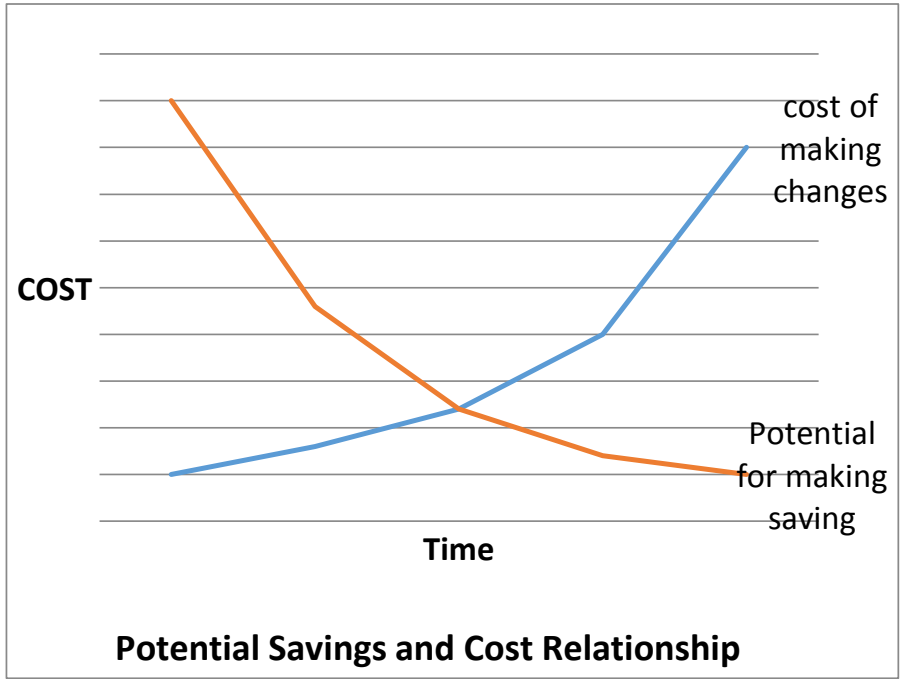




\title{
V. Conclusion
}

Evaluating all the project options by the same cost categories, over the same study period using the same discount rate the Life cycle costing can be carried out. The Process of carrying out the life cycle costing will increase the understanding of the proposed project among designers and project representatives. Often cost saving ideas can be generated that can be applied to more than one project options,these ideas can be directed towards the design of project to further enhance its profitability. The use of LIFE CYCLE costing enables projects to be evaluated by their long term cost rather than only the initial construction cost, the stress on future cost directly benefits project owners. A building design that minimises future operations and maintenance expenses leaves more money in the facilities operating budget, thus making more money available to project stakeholders.

\section{Acknowledgements}

6.1 Mr R K Jain. Principal DYPIET. Pune.

6.2 Mr YashwantAnantraj. MD SYconepmc. Bangalore.

6.3 Mr CharulVakta. Exe Director YMCAIC. Ahmedabad.

\author{
References \\ [1] ISO 15686-5:2008(E) \\ [2] The NIST handbook 135, 1995 Edition. \\ [3] Department of Education and Early Developments Cost Model Spreadsheet. \\ [4] New Southmwales Treasury - Total Asset management- Life cycle costing guideline.
}

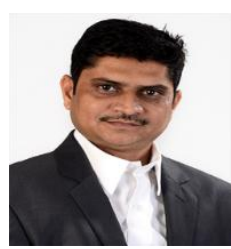

\section{Biographies}

Real Jagdish is a Post Graduate student at Padamshree Dr. D.Y Patil Institute of Engineering and Technology Pimpri, Pune 400018 and Senior Manager Projects With the reputed PMC Firm SyconeCpmc. Bangalore. He is credited with successful completion of projects like YMCA International Centre at Ahmedabad.

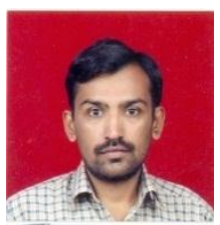

Rahul Patil is Assistant Professor in department of Civil Engineering, Padamshree Dr. D.Y Patil Institute of Engineering and Technology Pimpri, Pune 400018. With more than 12 years' experience in teaching and currently pursuing Ph.D. from University of Pune. 